\title{
Seizure developed after palonosetron intravenous injection during recovery from general anesthesia -A case report-
}

\author{
Pyung-Gul Park, Hwa-Yong Shin, Hyun Kang, Yong Hun Jung, Young-Cheol Woo, Jin-Yun Kim, \\ Gill Hoi Koo, Sun Gyoo Park, and Chong Wha Baek \\ Department of Anesthesiology and Pain Medicine, Chung-Ang University Hospital, Seoul, Korea
}

Seizure associated with antiemetics is rare. We report seizure associated with a $5-\mathrm{HT}_{3}$ receptor antagonist in a 38 years old female. The patient underwent ureterorenoscopic lithotripsy due to left upper ureter stone. After operation, the patient complained of nausea in the postanesthetic recovery unit. In order to subside symptom, the patient was administrated $5-\mathrm{HT}_{3}$ receptor antagonist, palonosetron, $0.075 \mathrm{mg}$ intravenously. Shortly after administration of that, the patient developed generalized tonic-clonic seizures. The symptom was subsided after midazolam and thiopental sodium were injected. But 40 minutes later, seizure recurred and subsided with midazolam again. The patient recovered completely without any specific sequelae. (Korean J Anesthesiol 2012; 63: 173-176)

Key Words: Palonosetron, Seizure, $5-\mathrm{HT}_{3} \mathrm{R}$ antagonist.

Various postoperative complications may occur due to many factors such as the general state of the patient, operated region, surgical procedure, administered drug, and genetic factors. Among the various postoperative complications, postoperative nausea and vomiting are the most common complications and they account for a considerable part of the quality of a patient's recovery. For this reason, antiemetics are used to prevent and treat postoperative nausea and vomiting. 5 -Hydroxytryptamine type 3 receptor $\left(5-\mathrm{HT}_{3} \mathrm{R}\right)$ antagonist is commonly used since it is known to have an excellent effect and causes fewer complications than that of other antiemetics. The rare side effects of $5-\mathrm{HT}_{3} \mathrm{R}$ antagonist include headache, fatigue, sedation, and constipation [1-4]. In a few cases, seizure has occurred after the injection of $5-\mathrm{HT}_{3} \mathrm{R}$ antagonist, which was reported to be suspected as the cause of the seizure [4-6]. Here, we experienced a seizure that developed after the injection of palonosetron, a second-generation $5-\mathrm{HT}_{3} \mathrm{R}$ antagonist, into a patient who had undergone an operation under general anesthesia for the treatment of postoperative nausea and vomiting and thus, report the case with a review of the relevant literature.

Received: September 7, 2011. Revised: October 6, 2011. Accepted: October 13, 2011.

Corresponding author: Chong Wha Baek, M.D., Department of Anesthesiology and Pain Medicine, Chung-Ang University Hospital, 224-1, Heukseok-1dong, Dongjak-gu, Seoul 156-755, Korea. Tel: 82-2-6299-2583, Fax: 82-2-6299-2585, E-mail: nbjhwa@naver.com (C) This is an open-access article distributed under the terms of the Creative Commons Attribution Non-Commercial License (http:// creativecommons.org/licenses/by-nc/3.0/), which permits unrestricted non-commercial use, distribution, and reproduction in any medium, provided the original work is properly cited. 


\section{Case Report}

A female patient, who was 38 years old, $158 \mathrm{~cm}$ tall and weighed $62 \mathrm{~kg}$, underwent ureterorenoscopic lithotripsy for the left upper ureter stone. There was no specific familial medical history, past medical history, or administered drugs. All the results of the preoperative laboratory tests done after the hospitalization including electrocardiogram, chest x-ray, blood examination, and urine examination were in the normal range.

Glycopyrrolate $0.4 \mathrm{mg}$ was intramuscularly injected as the preoperative treatment. After arriving at the operation room, the vital signs including blood pressure, electrocardiogram, oxygen saturation, heart rate, and respiratory rate were stable. Thiopental sodium $300 \mathrm{mg}$ was intravenously injected for induction and rocuronium $35 \mathrm{mg}$ after the loss consciousness. Following the injection, ventilation was performed with $100 \%$ oxygen and sevoflurane 3 vol\% until the vocal cords were fully relaxed. Intubation was performed after the vocal cords were relaxed fully. While maintaining anesthesia, ventilation was controlled so that the end tidal carbon dioxide tension could be kept at 30-35 mmHg. A concentration of 2-3 vol\% sevoflurane was controlled in the inhalation gas along with $50 \%$ oxygen and $50 \% \mathrm{~N}_{2} \mathrm{O}$ in order to maintain the depth of the anesthesia appropriate to the operation. The operation took about 25 minutes. Under the ureteroscopy, the ureter stones were crushed and then eliminated. Four liters of normal saline solution was used as the irrigation solution. At the end of the operation, pyridostigmine $15 \mathrm{mg}$ and glycopyrrolate $0.4 \mathrm{mg}$ were intravenously injected after spontaneous breathing was recovered for complete recovery from the muscle relaxant. Extubation was performed after consciousness was recovered. The patient was transferred to the recovery room after the patient's spontaneous breathing and vital signs were stabilized.

When the patient arrived at the recovery room, the vital signs were stable. Using a venturi mask, oxygen $5 \mathrm{~L} / \mathrm{min}$ was supplied at a inspired oxygen fraction 0.4. After ten minutes, the oxygen supply through the venture mask was stopped and oxygen saturation was continuously kept at $100 \%$ on the pulse oximetry. Twenty minutes after arriving at the recovery room, the patient complained of nausea, and thus, palonosetron $0.075 \mathrm{mg}$ was intravenously injected. Seventeen minutes after the palonosetron injection, the patient felt the onset of a bowel movement. While attempting defecation with a bedpan in bed in the recovery room, the patient showed a sudden involuntary movement of four limbs. At the time of the moment when the symptoms were found, midazolam $2 \mathrm{mg}$ and thiopental sodium $50 \mathrm{mg}$ intravenously injected one by one, and oxygen $5 \mathrm{~L} / \mathrm{min}$ was supplied using a venturi mask. Whether there was loss of consciousness during the involuntary movement was not clear and whether there was eyeball deviation was not verified. The patient trembled while stretching her four limbs, showing the pattern of a generalized tonic-clonic seizure. There was not salivation, urination, and tongue bite. At that time, the systolic pressure was $125 \mathrm{mmHg}$, diastolic pressure $80 \mathrm{mmHg}$, and heart rate $72 / \mathrm{min}$, showing no abnormal findings in the blood pressure, heart rate, and electrocardiography. The involuntary movement disappeared after the injection of midazolam and thiopental sodium. Forty minutes after the symptoms, the patient's consciousness became clear, and her vital signs were stabilized. Thus, recovery room monitoring was finished. A brief neurological examination performed at that time did not show any abnormal findings. While waiting for radiography immediately after being discharged, the patient showed the same pattern of involuntary movement and consciousness was temporarily lost. The patient was immediately transferred to the recovery room where midazolam $2 \mathrm{mg}$ was intravenously injected and oxygen $5 \mathrm{~L} / \mathrm{min}$ was supplied using a venturi mask again. An arterial blood gas analysis and electrolyte test were performed and the results showed a $\mathrm{pH} 7.40, \mathrm{PaO}_{2} 156 \mathrm{mmHg}$, $\mathrm{PaCO}_{2} 39 \mathrm{mmHg}$, sodium $143 \mathrm{mEq} / \mathrm{L}$, potassium $3.7 \mathrm{mEq} /$ $\mathrm{L}$, and chloride $106 \mathrm{mEq} / \mathrm{L}$. The body temperature was $36.4^{\circ} \mathrm{C}$ and the blood sugar level was $81 \mathrm{mg} / \mathrm{dl}$. After the injection of midazolam, the symptoms disappeared and did not recurrence. Since the patient's consciousness recovered and her vital signs were stabilized, she was transferred to the ward one hour after returning to the recovery room.

The symptoms did not reoccur during her hospitalization and the postoperative test did not show any abnormal findings. Thus, the patient was discharged two days after the operation. The postoperative follow-up for six months showed that the seizure had not reoccurred.

\section{Discussion}

Currently, various drugs including $5-\mathrm{HT}_{3} \mathrm{R}$ antagonist, dopamine antagonist, corticosteroid, histamine antagonist, anticholinergics, and neurokinin receptor antagonist are used to prevent and treat nausea and vomiting based on different mechanisms. Among them, $5-\mathrm{HT}_{3} \mathrm{R}$ antagonist prevents nausea and vomiting by selectively blocking $5-\mathrm{HT}_{3} \mathrm{R}$ at the gastrointestinal vagus afferent nerve, the chemical receptor in the brain stem, and the solitary nucleus $[1,2]$. Ondansetron, granisetron, ramosetron, and palonosetron are the representative $5-\mathrm{HT}_{3} \mathrm{R}$ antagonistic drugs. Different from other antiemetics, they have no side effects such as sedation or extrapyramidal symptom, having less generalized action and showing an excellent effect as an antiemetic, and thus, they are most frequently used in recent times [1-3].

Since the side effects by the administration of $5-\mathrm{HT}_{3} \mathrm{R}$ antagonist are relatively rare or mild in general, being temporary 
and moderate, it is known that there is almost no case where the administration of the drug has to be stopped [1]. The most common side effect is headache, mild to moderate, which is treated with nonopioid analgesics. Additionally, constipation may occur due to a side effect in the gastrointestinal system, and the hepatic enzyme level may be increased. An electrocardiographic change such as an increased QT interval may be observed, which is clinically insignificant, and the correlation of the change with the $5-\mathrm{HT}_{3} \mathrm{R}$ antagonist is not clear $[1,2]$.

There are a few cases, like our case, where a seizure occurred after the injection of $5-\mathrm{HT}_{3} \mathrm{R}$ antagonist. An accurate mechanism has not been clarified yet but $5-\mathrm{HT}_{3} \mathrm{R}$ antagonist is considered as the cause because other factors of seizure have been excluded in these patients [4-6]. Singh et al. [5] reviewed the medical records of 1,521 patients who underwent ondansetron injection for nausea and vomiting. They found that generalized tonic-clonic seizure lasting 1 minute or less, occurred in three patients among them within 12-22 minutes after the intravenous injection of ondansetron $4 \mathrm{mg}$. these patients showed normal findings in all the tests except only one showed mild hypokalemia. The electroencephalography and MRI test that were performed later also showed normal findings. No patients showed any signs for recurrence of the seizure for more than six months in the absence of antiepileptic drugs. In other words, the patients who showed seizure did not have any inducers of seizure. Considering the temporal relationship between the injection of ondansetron and the occurrence of the seizure, which is that the seizure occurred at the time when the injected ondansetron might have reached a significant concentration at the central nervous system, ondansetron, which is one type of $5-\mathrm{HT}_{3} \mathrm{R}$ antagonist, is suspected as the cause of the seizure. Recently, Zambelli et al. [4] reported a case of a patient to whom palonosetron $0.25 \mathrm{mg}$ was injected for prevention of chemotherapy induced nausea and vomiting. One hour after the palonosetron injection, a generalized tonicclonic seizure that lasted for eight minutes occurred and was treated with diazepam. In this case also, there was no other finding that could be suspected as the cause for the seizure except palonosetron. In our case also, there were no other factors that could be suspected as the cause for the seizure in the past medical history including the family medical history as well as in the test results. Although a definitive diagnosis of a seizure could not be made by electroencephalogram or MRI imaging immediately after the occurrence of the seizure, the patient showed a pattern for generalized tonic-clonic seizure as in the previous cases. The patient was sedated by midazolam injection. In the occurrence of the second seizure, the loss of consciousness was certain. After that, the patient recovered without any complications or recurrence.

Epilepsy is a heterogeneous disease group caused by various factors. Epilepsy, which secondarily occurs by abnormal synchronous discharges of the nervous system network, is triggered by abnormal ionic conduction, changes in neuronal membranes, and an imbalance between excitatory and inhibitory influences. It was shown that 5-HT neurotransmission is involved in the control of seizure induced in various types of experiments. In general, drugs that increase the extracellular 5-HT level repress an seizure and the depletion of cerebral 5-HT increases the sensitivity to convulsions. Among the various subtypes of 5 -HTR, at least $5-H_{1 A} R, 5-H_{2 c} R$, $5-\mathrm{HT}_{3} \mathrm{R}$ and $5-\mathrm{HT}_{7} \mathrm{R}$ are known to be associated with epilepsy [7].

Therefore, it is assumed that $5-\mathrm{HT}_{3} \mathrm{R}$ antagonists may have a direct or indirect effect on the process involved in seizure, and $5-\mathrm{HT}_{3} \mathrm{R}$ antagonists including ondansetron may be considered as proconvulsants or anticonvulsants of convulsion [5]. Although $5-\mathrm{HT}_{3} \mathrm{R}$ antagonists selectively act on the $5-\mathrm{HT}_{3} \mathrm{R}$, the possibility still remains that they may act on other 5-HTRs such as $5-\mathrm{HT}_{1}, 5-\mathrm{HT}_{2}$, and $5-\mathrm{HT}_{4}$ receptors as well as $\mu$-opioid, $\alpha$-adrenergic, $\gamma$-aminobutyric acid (GABA), and glycine receptors that belong to the same ligand gated ion channel [8]. Ye et al. [9] assumed that the clinical occurrence of an seizure due to ondansetron may be caused by the inhibition of the GABA and glycine receptor activity. Grant et al. [10] also reported that MDL 72222, a $5-\mathrm{HT}_{3} \mathrm{R}$ antagonist, exacerbated ethanol withdrawal seizure.

On the contrary, Wada et al. [11] reported that phenyl-biguanide, a $5-\mathrm{HT}_{3} \mathrm{R}$ agonist, extended the duration of seizures in amygdala kindling occurs. Many animal experiments $[11,12]$ have also shown that the occurrence of seizure was repressed by $5-\mathrm{HT}_{3} \mathrm{R}$ antagonists such as zacopride, granisetron and ondansetron. Moreover, considering the fact that the seizures developed after a $5-\mathrm{HT}_{3} \mathrm{R}$ antagonist injection occurred following a normal dose of it including our case and they actually occurred in extremely rare cases, further study and investigation may be required on the role of $5-\mathrm{HT}_{3} \mathrm{R}$ in seizures and on its mechanism. However, in all the seizure cases described above, the $5-\mathrm{HT}_{3} \mathrm{R}$ antagonist was injected when the patients were conscious. Since $5-\mathrm{HT}_{3} \mathrm{R}$ antagonist injection is mostly performed during anesthesia in order to prevent postoperative nausea and vomiting, the occurrence of seizures might have been hid or repressed by general anesthesia or muscular relaxation, and thereby, the occurrence rate might have been underestimated.

On the other hand, palonosetron, a new, second generation $5-\mathrm{HT}_{3} \mathrm{R}$ antagonist based on the fused tricyclic ring to which a part of quinuclidine is attached, induces its effect by blocking serotonin binding, causing a structural change in the receptor, different from the first generation $5-\mathrm{HT}_{3} \mathrm{R}$ antagonists such as ondansetron and granisetron that act as competitive repressors to $5-\mathrm{HT}_{3} \mathrm{R}$, having a similar structure to that of the $5-\mathrm{HT}_{3} \mathrm{R}[13]$. 
Palonosetron is known to act more selectively since it has a high affinity to $5-\mathrm{HT}_{3} \mathrm{R}$ and has a half-life as long as 40 hours $[4,14]$. Thus, in comparison to the first generation $5-\mathrm{HT}_{3} \mathrm{R}$ antagonists such as ondansetron, palonosetron may have less risk of causing an seizure by not acting on other receptors that are related to the seizure process except for $5-\mathrm{HT}_{3} \mathrm{R}$. However, considering the seizure in our case in which the patient had been subsided by the injection of midazolam and recurrence after 40 minutes, seizure may last longer once it occurs and it may require longer hours of monitoring since its effective time is longer.

In conclusion, $5-\mathrm{HT}_{3} \mathrm{R}$ antagonists are commonly used in clinics since they are effective in the prevention and treatment of postoperative nausea and vomiting and rarely show complications. Although rare, there is a risk of seizure by the administration of $5-\mathrm{HT}_{3} \mathrm{R}$ antagonists. Even though seizure seems to be a temporary benign complication, it may cause a severe problem in some patients including cardiopulmonary compromised patients. Therefore, care should be taken when injecting a $5-\mathrm{HT}_{3} \mathrm{R}$ antagonist, especially when injecting into a conscious patient. Further studies may need to be done on the incidence rate of seizure developed after $5-\mathrm{HT}_{3} \mathrm{R}$ antagonist injection and on its mechanism.

\section{References}

1. Gregory RE, Ettinger DS. 5- $\mathrm{HT}_{3}$ receptor antagonists of the prevention of chemotherapy-induced nausea and vomiting. A comparison of their pharmacology and clinical efficacy. Drugs 1998; 55: 173-89.

2. Harvey RA, Champe PC, Howland RD, Mycek MJ. Lippincott's illustrated reviews pharmacology. 4th ed. Lippincott Williams \&
Wilkins: Philadelphia. 2008, pp 335-8.

3. Rüsch D, Eberhart LH, Wallenborn J, Kranke P. Nausea and vomiting after surgery under general anesthesia: an evidence-based review concerning risk assessment, prevention, and treatment. Dtsch Arztebl Int 2010; 107: 733-41.

4. Zambelli A, Sagrada P, Pavesi L. Seizue associated with palonosertron. Support Care Cancer 2009; 17: 217.

5. Singh NN, Rai A, Selhorst JB, Acharya JN. Ondansertron and seizures. Epilepsia 2009; 50: 2663-6.

6. Shrma A, Raina V. Generalised seizures following ondansetron. Ann Oncol 2001; 12: 131-2.

7. Bagdy G, Kecskemeti V, Riba P, Jakus R. Serotonin and epilepsy. J Neurochem 2007; 100: 857-73.

8. Ye JH, Ponnudurai R, Schaefer R. Ondansetron: a selective 5-HT(3) receptor antagonist and its applications in CNS-related disorders. CNS Drug Rev 2001; 7: 199-213.

9. Ye JH, Schaefer R, Wu WH, Liu PH, Zbuzek VK, Mcardle JJ. Inhibitory effect of ondansetron on glycine response of dissociated rat hippocampal neurons. J Pharmacol Exp Ther 1999; 290: 104-11.

10. Grant KA, Hellevuo K, Tabakoff B. The 5-HT3 antagonist MDL72222 exacerbates ethanol withdrawal seizures in mice. Alcohol Clin Exp Res 1994; 18: 410-4.

11. Wada Y, Shiraishi J, Nakamura M, Koshino Y. Effects of the 5-HT3 receptor agonist 1-(m-chlorophenyl)-biguanide in the rat kindling model of epilepsy. Brain Res 1997; 759: 313-6.

12. Semenova TP, Ticku MK. Effects of 5-HT receptor antagonists on seizure susceptibility and locomotor activity in DBA/2 mice. Brain Res 1992; 588: 229-36.

13. Watanabe K, Minabe Y, Ashby CR Jr, Katsumori H. Effect of acute administration of various 5-HT receptor agonists on focal hippocampal seizures in freely moving rats. Eur J Pharmacol 1998; 350: 181-8.

14. Yang LP, Scott LJ. Palonosetron: in the prevention of nausea and vomiting. Drugs 2009; 69: 2257-78. 